\title{
Rohingya Refugees Employment Readiness to Malaysian Labour Market: Challenges and the way forward
}

\author{
Mohd Safwan Ghazali¹, Tan Peck Leong², Sazlin Suhalmie Shariff ${ }^{3}$ \\ 1 Universiti Malaysia Kelantan \& Centre for Postgraduate and Professional Studies, ${ }^{2}$ Arshad Ayub Graduate Business School, \\ ${ }^{3}$ Centre for Postgraduate and Professional Studies, Faculty of Business and Administration, \\ Universiti Teknologi MARA, Shah Alam, 40450. Selangor. Malaysia \\ safwan.g@umk.edu.my; pecktan1@gmail.com; shariffsazlin@gmail.com \\ Tel of 1 st Author: +60134903920
}

\begin{abstract}
A refugee in Malaysia cannot work legally due to this nation has not acceded to the 1951 Refugee Convention or its 1967 Protocol. This protracted circumstance has led the refugee community to work illegally. Analysis from literature found that the Rohingya refugees are not suitable to work in confined environment and less job mobility, which partly due to human capital constraints and some job mismatch issues. Future research is called to gain empirical data on understanding the readiness, challenges, and strategies to be implemented. The article is prominent in assisting the government in providing a clear stance on the role of Rohingya refugees in the Malaysian labor market.
\end{abstract}

Keywords:Rohingya refugees; Employment; Labour Market; Readiness

eISSN: 2398-4287@ 2020. The Authors. Published for AMER ABRA cE-Bs by e-International Publishing House, Ltd., UK. This is an open access article under the CC BYNC-ND license (http://creativecommons.org/licenses/by-nc-nd/4.0/). Peer-review under responsibility of AMER (Association of Malaysian Environment-Behaviour Researchers), ABRA (Association of Behavioural Researchers on Asians) and cE-Bs (Centre for Environment-Behaviour Studies), Faculty of Architecture, Planning \& Surveying, Universiti Teknologi MARA, Malaysia. DOI: https://doi.org/10.21834/ebpj.v5i14.2099

\subsection{Introduction}

The incredible journey and struggle to reach the shore can be an extremely daunting task and drastically hard for refugees. The vast majority of newly displaced people were focused between 2011 and 2016, driven mostly by the Syrian conflict and Rohingya persecution in Myanmar (UNHCR, 2016). Another essential feature of the current forced migration trend is the vast movement of forcibly displaced persons to seek asylum in developing countries, including Malaysia (S. Y. Cheung \& Phillimore, 2017). This is particularly true as Malaysia is the tenth highest in Asia and the Pacific region and the first rank in the Southeast Asia region receiving country of refugees (UNHCR, 2017). Apart from the Philippines and Cambodia, Malaysia and other Southeast Asian nations do not have signatory parties to the United Nations Refugee Convention 1951, neither of which was a 1967 protocol. In turn, they do not distinguish refugees from other undocumented migrants, or in other words, they perceived refugees as 'illegal' migrants (A. Kaur, 2008). For this uncertain status, most refugee population concentrated in the urban areas and have experienced hurdles to earn livelihood in Malaysia (S. Cheung, 2011) and the majority of refugees work in the informal sector, but under much less satisfactory and more exploitative conditions compared with other economic migrants (Zetter \& Ruaudel, 2016b). In the Malaysian context, they have minimal access to legal employment, formal education, and affordable health care (Ghazali, Peck Leong, \& Subramaniam, 2018)

Consistently, the number of refugees in Malaysia is growing. As of the end of February 2020, some 178,990 refugees and asylumseekers have registered with United Nations High Commissioner for Refugees (UNHCR) in Malaysia. The number has increased from the previous year, with many more still unregistered. As delineated in Table 1, most of them come from the Rohingya ethnic group, from Myanmar, and the rest come from countries such as Pakistan, Yemen, Syria, and others (UNHCR, 2020b). In light of this scenario, it is 
becoming tough to ignore the presence of refugees in the Malaysian narrative (Wake \& Cheung, 2016). However, little is known about the employment narrative of Rohingya refugees in Malaysia. Despite not having the legal rights to work, many of refuges work in the lowest paying jobs (3D jobs) that the local does not wish to engage and relocate mainly in vulnerable areas (Wake \& Cheung, 2016). Hence is aimed for the present paper to provide some valuable insights on the Rohingya refugee's readiness to be part of the legal labour source if the Malaysian government takes forward to legalized refugees with employment rights. Therefore, the present paper discusses the benefits of giving refugees the right to work, readiness, and challenges that could affect the host labour market.

Table 1: Refugees and Asylum-Seekers Registered with UNHCR in Malaysia.

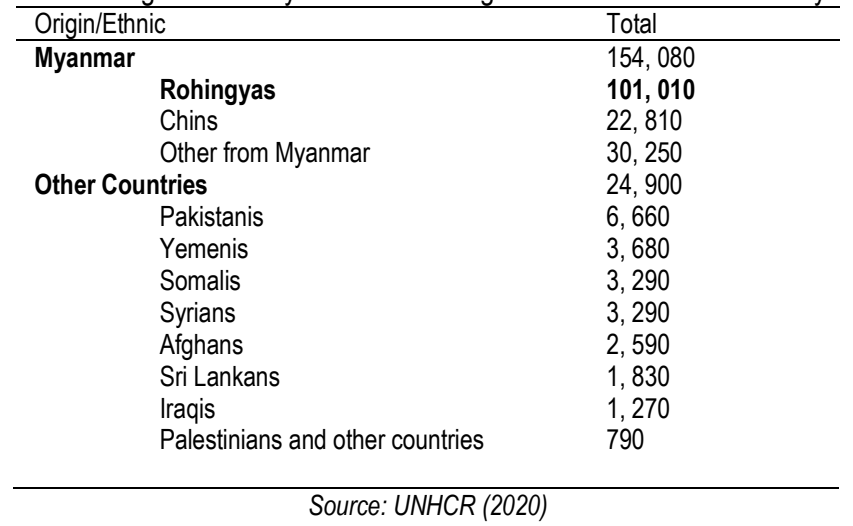

\subsection{Literature Review}

\subsection{Refugee Vs. Malaysian Dilemma}

Where peace is fragile, refugees are unable to return to their homes or are unable to stay in host countries, thus repatriate to the third country was the preferred solution for them to retain protection and rebuild their lives. However, to be relocated, fortunate refugees may only wait 2-5 years, but many of them are left waiting for more than ten years or likely to stay 'permanently' in the host country. In the present global context, strengthening the existing labor market and granting refugees the right to work in the host country is imperative. Generally, a refugee in Malaysia cannot work legally and have minimal access to quality healthcare, and education due to this nation has not acceded to the 1951 Refugee Convention or its 1967 Protocol. As such, this 'dilemma' situation has led the refugee community vulnerable to exploitation, arbitrary, and detention by local authorities because of their 'illegal or undocumented migrants' status.

The UNHCR primary purpose is to leading and managing the global security of Refugees and assisting in solving the refugee problem. According to UNHCR (2016) defines a refugee is an individual who has been a force to flee from his country of origin due to on-going war, violence and, persecution. In other words, refugees here in Malaysia are classified as forced migration since they have pushed too. They are unlike other economic migrants who have temporarily left their country seeking a better life and could always return home peacefully. UNHCR As informed in the earlier section, refugees and asylum seekers currently have successfully selfintegrated into Malaysian multi-ethnic society and culture (Don \& Lee, 2014). This is the fact that we, as a Malaysian and fellow human beings, cannot turn blind eyes. Notable, Employment Act in Malaysia has officially prohibited them from work. Still, circumstances force them to engage with informal jobs, opening a small business, enduring risk and hardship to earn some money and support their families (Wake \& Cheung, 2016). Additionally, the system also puts compassionate employers who employ them, or want to hire, in a bind.

\subsection{Malaysia Government Attention on Granting Refugee Rights to Work}

Refugee rights to work in Malaysia were previously granted through issuance of IMM13 permit, a temporary residence permit issued by the Ministry of Home Affairs under section 55(1) of its Immigration Act (Abd Jalil, 2016). The issuance of IMM13 is meant for the identification of the refugees, which also allowing refugees to work, have minimal access to education and health in Malaysia. However, this permit expires in 12 months, with a fee of RM90 and no guarantee that the renewal of the permit granted (Yasmin, Daniel, \& Fauzi, 2019). The pain of issuing this permit began to be felt by the ministry when Malaysia was flooded with Rohingya refugees. At that time, the IMM13 permit was the best hope for these refugees to get the right to work. However, their dreams declined when the permit application process was halted without warning and suspended on allegations of corruption involved in the registration process (SUARAM, 2008).

The government's interest in granting the refugees rights to work transpired again in February 2016. Subsequently, a pilot project was announced for 300 Rohingya to work in the plantation and manufacturing sectors (Yasmin et al., 2019). This project is expected to broaden work schemes for refugees in Malaysia and help the government better manage the refugees' group (Beh, 2016). In March 2017, the government launched the first phase of the three-year pilot project to grant work permits to 300 Rohingya-registered refugees (The Sun Daily, 2017). The project, however, has seen to be unsuccessful since $98 \%$ of participants had left the site and leave only two persons remains (Lokman, 2017). There is low interest among the refugees, and the first phase of the project concluded that the plantation sector was not a good fit for the Rohingya refugees. The second phase of the project involves the manufacturing industry commencing in September 2017 with its first batch. It had seen some success when the company participated and employed the second 
batch of refugees worker to work in the company (JREC, 2019). However, the number of refugees registered for the pilot project was less than 100, which was less than what has been targeted (Bernama, 2017).

\subsection{Methodology}

As estimated in the IDEAS policy paper, the country would benefit from RM3 billion to its annual GDP through higher spending and earned nearly RM50 million in tax each year by 2024 if refugees are allowed to participate in the host labour market (Todd, Amirullah, \& Shin, 2019). This paper focuses on the response concerning the readiness of Rohingya refugees to work. This area is chosen due to its lack of research in previous literature on this 'hidden' group, especially from an economics standpoint. Hence, arguments are presented in the form of critical analysis from past and present research studies. The outcomes of the present study are derived from the working paper, policy ideas, government reports, and newspaper/web page articles.

\subsection{Findings and Discussion}

\subsection{The Effects of Granting Refugees Rights to Work: Major Host Countries}

Researchers acknowledge that the evidence supporting the effects of refugees' employment on the host labour market is relatively low and insufficient. In this section, the analysis concentrates on the refugee's employment impact of other host countries, especially those who are not a party to either the 1951 Refugee Convention or its 1967 Protocol. Despite its resource constraints, Bangladesh has welcomed refugees on the humanitarian agenda (Imran \& Mohammad, 2014). Accordingly, as of September 2019, 819,787 Rohingya refugees were registered under the Government of Bangladesh-UNHCR registration exercise. There are also 34,917 registered refugees from the pre-existing and registered camps. Refugees in Bangladesh have no right to work. However, unofficial work inside and outside the camps is still acceptable. Both registered and non-registered Refugees have to involve in informal jobs and become economically self-reliant (Zetter \& Ruaudel, 2016a). Among the informal economy activities done by the refugees inside the camp are floor mat making, soap production, carpentry, mobile phone, and rickshaw repairs, there are small shops in the camps selling various commodities (Zetter \& Ruaudel, 2016a). Notably, these refugees have no other choice but have to accept the job due to social isolation (anti-Rohingya sentiments), illiteracy, and other skills shortages (Imtiaz, 2010).

Following, Pakistan keeps hosting refugees for more than 40 years (Zaafir, 2020). These refugees are assigned to register for Proof of Registration (PoR) cards, which entitle them to freedom of movement and temporary legal status in Pakistan (UNHCR, 2020a). There is still no clear stand or structure for the refugees from the government standpoint in terms of working right. Even refugees with PoR cards are not restricted from performing any lawful occupation in Pakistan; they cannot access any jobs in the government service (Zetter \& Ruaudel, 2016a). However, the Pakistani government does not have a strict policy on refugee work permits in informal sectors (Clemens, Huang, \& Graham, 2018). This, in turn, allows refugees to work in factories, shops, and other places of work to earn for living. However, given inadequate human capital and financial capacity also prevents refugees from learning marketable skills that limit them to finding job opportunities in emerging markets or sectors. Moreover, refugees are perceived to be more efficient than local people in the host country in the low-end labour market (Mohmand, 2010).

By comparison, Turkey is a member of the Party to the 1951 Convention and the 1967 Protocol. Turkey is hosting nearly 4.1 million refugees and asylum seekers from Syria and other countries, and it continues to become the largest refugee host in the world. Concerning employment opportunities to refugees, the Regulation on Work Permit of Refugees under Temporary Protection was issued by the government of Turkey. This regulation aims to help Syrian refugees become economically independent, intending to increase their self-reliance on social needs and contribute to the Turkish economy through integration into the labour market (Carpio, Seker \& Yener, 2018). This regulation gives the refugees the right to formally access work permits under certain conditions and with some restrictions. It states that foreign nationals with refugee status or under temporary protection have the right to work for their employer or on their account upon receiving their legal status. However, access is limited by the market sector, geographical area, or profession as required by labour market conditions (International Labour Organization, 2019). As shown in figure 1, the vast refugee workforce is employed in the textile industry, followed by trade and hospitality, manufacturing, and construction.
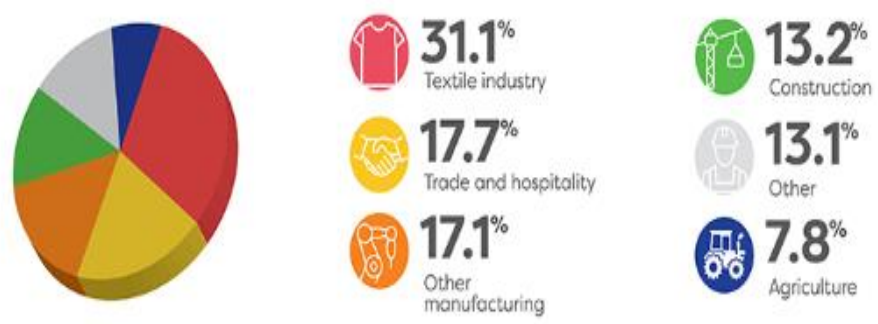

Figure 1: Refugees in the Turkish Labour Market Source: International Labour Organization (2019) 


\subsection{Rohingya Refugees in the Malaysian labour market}

Refugees in Malaysia are engaged in informal economy activities and mainly reside in urban living areas, with the majority of them are concentrated in Klang Valley (Ghazali et al., 2018). As shown in figure 2, out of 180,000 registered refugees in Malaysia, $40 \%$ or around 70000 are estimated to participate in the labour market, most of them illegally in lower-skilled and low earning jobs. However, there is no official data published on Rohingya refugee's participation in the Malaysia labour market. But this present study believes Rohingya ethnic comprised as a majority of the estimated figures. Although an important indicator, not all the working-age populations are managed to get hired. This is unsurprising, given the statistics by UNHCR, relatively the labour participation rates among refugees and asylum seekers are reported about $50 \%$ of the total population. These figures may underlie some issues regarding the refugee's participating in the Malaysian labour market. These include the fear of getting arrested, poor access to employment opportunities, exploitation, language and cultural barriers, negative stigma towards refugees, and other micro issues related to family structure.

Linking these problematic conditions with the Malaysian lens consequently brought various pieces of evidence. To date, there is only one empirical study done by Nungsari \& Flanders (2018) conducted on Rohingya refugees labour participation in the Malaysia labour market. The study was carried out on Rohingya, who currently worked in the construction sector. From the 288 responses with numbers of the focus group, the discussion involved the Rohingya community leader; this study has highlighted some valuable findings to discusses. In general, the research suggests that Rohingya has low educational attainment, and many of them are illiterate. As a result, they are easy to be exploited by the employer and local authorities. Consequently, almost all the respondents said that they get arrested at least once and revealed that they have to pay between RM450-RM600 to be let out by local authorities. In terms of earning, respondents said they could average RM 1420 a month or around RM55 daily wage. Surprisingly, this shows that Rohingya refugees are made above the minimum wage and contribute to fiscal consumption through high spending on groceries, rent, bills payment, and remittance. As mentioned earlier, the government pilot project on Rohingya has seen to be unsuccessful and struggle to retain participants, which can be explained Nungsari \& Flanders (2018) research findings. First, the demographics of this Rohingya is different comparing to the other economic migrants. Most of the Rohingya reported ties with their immediate families (spouse, child, or parents) and stayed together as a community. So, it's hard for them to work on isolation plantations or far from home. Without access to transportation (if any, required some costs), many of them inclined to work closely on their living areas. Second, the salary offered, as they can earn more on working in informal jobs, thus pursued on government official project is not favorable for them. In short, although construction is not a traditional occupation for them in Myanmar and they don't have the specific skills and knowledge, the income earned can be their pulling factor to remain and absorb the related risk.

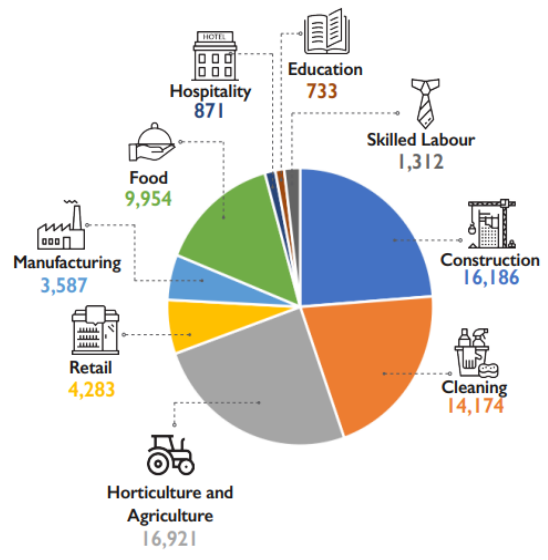

Figure 2: UNHCR Registered Refugees and Asylum Seekers in Malaysia by Sector of Employment, January 2019 Source: Todd, Amirullah, \& Shin (2019)

\subsection{Challenges and Strategies for improving Refugees Access to Employment}

No legal framework, language barriers, cultural differences, inadequate human capital, low wages, unsecured working place, antirefugee sentiments and less job mobility in the informal economy reported as challenges to refugees employment. Poor language competence, less educational attainment and some required job skills which lead to another gateway to inclined in employment challenges (Buber-Ennser et al., 2016; Dubus, 2017; Nungsari \& Flanders, 2018; OECD, 2016). Additionally, for the refugees seeking to work professionally, they have faced more challenges in ensuring their qualification to be recognized in the host country. No legal framework is the primary concern to Rohingya refugees in Malaysia as they are exposed to exploitation, bribes, abuse and detention (Nungsari \& Flanders, 2018; Wake \& Cheung, 2016). On the same note, with current status, refugees can never plan their careers. They are just doing survival jobs. Besides, transitioning skills and experience from refugee home country also another challenge to refugee employment, as well as less job mobility would increase job mismatches among the refugee workforce (Nungsari \& Flanders, 2018; Wake \& Cheung, 2016). Moreover, for Rohingya where mostly illiterate and limited job exposure, many of them would face difficulties to integrate with local culture, norms and attitude; as a result, it creates the anti-Rohingya sentiments among the locals (Aljazeera, 2020; M. Kaur, 2020; S.B, 2020). Given this, Rohingya refugees mostly lack in all aspects than other refugee counterparts, which could be a more challenging issue to get employed and pursue their livelihoods in Malaysia. 
Discussing the effects of granting refugees rights to work and some challenges concerning employment opportunities. The next section attempts to provide several strategies that refugees, employers, policymakers, locals, and other stakeholders could embark on and make some significant adjustments to the labor market. Almost the majority of past studies point out limited language competence and lack of skills in employment; as a result, refugees are surrounded in low-paying jobs. Therefore, it is suggested the need for continuous education and job training. The work preparedness workshop is imperative to provide the refugees with the standard skills needed and rights attitude to increase job retention and job search. It is suggested to government together with employer, UNHCR, and NGOs to develop the module, which covers job skills, language proficiency, digital literacy, health and personal hygiene, work ethics, basic financial literacy, and host culture.

Next, to improve refugee incomes or at least partly with other migrant workers, a specific legal status has to be exercised to lift the employment barriers-the clear legal framework that aims to protect the refugees, employers, and benefit the country. We acknowledged it's not an easy decision to made by the authorities due to the complexity of the refugee status. Yet, we still failed to tackle the influx of illegal foreign workers in labour market. But this issue can't be ignored, yet the country needs a durable solution. Malaysia may stand not to sign the refugee convention, but the authorities require to develop a creative mechanism to tackle this employment issue. That mechanism or such program needs to consider providing refugees with full job mobility and are not confined to specific industries or locations, as suggested by Todd et al., (2019). Although vast of the refugees reported are illiterate and have limited skills, but there are some with tertiary education backgrounds that are poorly matched to 3D jobs.

Last but not least, the government pilot project must also consider the sociodemographic factor and not treat them as equal to other foreign workers (Bernama, 2017). As suggested by Nungsari \& Flanders (2018), the household composition of Rohingya refugees is significantly different compare with other economic migrants. They are ties with the families; many of them stayed together with parents, spouses, and children. Thus, job sites cannot pull them away from the communities. It is suggested, the job sites are within walking distance and convenient to Rohingya centers. On the same note, it also helps the authorities monitor their movement and the population size to make sure the country is not exceeding its capacity to host refugees. Apart from that, the advocacy program to educate the locals on the refugee's issues also needs to be considered as well as an awareness program to the refugee community on the do's and don'ts while in Malaysia. Currently, there are lots of misunderstandings and misconceptions about them, which also may limit their opportunities to be employed (Kaos, 2017; S.B, 2020). Table 2 below is tabulated to assist the reader in understanding some strategies to overcome the barriers to refugee's employment readiness, specifically on the Rohingya sample.

Table 2: Strategies to Counter the Barriers to Refugees Employment Readiness

\begin{tabular}{ll}
\hline Barriers to Employment & Strategies to Employment \\
\hline No legal framework & Develop refugee policies, long-term and short-term plans \\
Human capital constrains & Continuous education and work preparedness training \\
Low wages & Improve the job matching and job mobility \\
Social perceptions & Advocacy program and awareness on refugee issue to locals understanding \\
Demographic constraints & $\begin{array}{l}\text { Develop profiling which contained refugees demographic, skill, values and } \\
\text { aspirations }\end{array}$
\end{tabular}

\subsection{Conclusion}

Moving forward, the perception of "temporary hosting" had facilitated the Malaysian government to withdraw less efforts to integrate refugees presence in some employment policies, which in turn not preparing the ecosystem (government, refugee, employer and community) for long term economic and social threat. Malaysian labour market relies greatly upon cheaper foreign workers reflected by the fact that more than 1.7 million in Malaysia are migrant workers (Ang Jian Wei, Murugasu, \& Yi Wei, 2017). This situation signifies that Malaysia is facing labour shortage. Yet, we exclude refugees who fit our economic and demographic needs. Nonetheless, a limited existing study has devoted their interest concerning the refugees employment readiness in Malaysian narrative. Thus, the present article suggests for future research endeavors to exploring this matter by collecting both side perspectives, employees an employer to obtain more accurate results. Conclusively, it is seen that further ignoring the issue without realizing ignoring the issue will cause more problems to host labour market.

\section{Acknowledgements}

The authors would like to thank the Ministry of Higher Education Malaysia for the financial support through the Fundamental Research Grant Scheme (FRGS), File No: FRGS/1/2019/SS08/UITM/02/7 and the Research Management Centre, Institute of Research Management \& Innovation (IRMI) Universiti Teknologi MARA, Shah Alam for managing the fund.

\section{References}

Abd Jalil, A. (2016). Refugees' right to work. The Star Online. Retrieved from https://www.thestar.com.my/opinion/letters/2016/06/18/refugees-right-to-work/

Aljazeera. (2020, May 11). Malaysia urged to end violent threats against Rohingya refugees | Malaysia News | Al Jazeera. Retrieved May 14, 2020, from Aljazeera News Malaysia website: https://www.aljazeera.com/news/2020/05/malaysia-urged-violent-threats-rohingya-refugees-200511035157656.html 
Ang Jian Wei, Murugasu, A., \& Yi Wei, C. (2017). Low-Skilled Foreign Workers' Distortions to the Economy. Retrieved from https://www.bnm.gov.my/files/publication/ar/en/2017/cp01_001_box.pdf

Beh, L. Y. (2016, November 24). Malaysia in pilot scheme to allow Rohingya refugees to work . Retrieved May 13, 2020, from Reuters website: https://www.reuters.com/article/us-malaysia-refugees-rohingya-idUSKBN13J1F1

Bernama. (2017). Only 40 Rohingya UNHCR Cardholders Registered For Work Under Pilot Scheme. Retrieved June 24, 2018, from Bernama website: http://www.bernama.com/en/general/news.php?id=1344343

Buber-Ennser, I., Kohlenberger, J., Rengs, B., Al Zalak, Z., Goujon, A., Striessnig, E., ... Lutz, W. (2016). Human capital, values, and attitudes of persons seeking refuge in Austria in 2015. PLOS ONE, 11(9), 1-29. https://doi.org/10.1371/journal.pone.0163481

Cheung, S. (2011). ' Migration Control and the Solutions Impasse in South and Southeast Asia : Implications from the Rohingya Experience .' Journal of Refugee Studies, 25(1). https://doi.org/10.1093/jrs/fer048

Cheung, S. Y., \& Phillimore, J. (2017). Gender and Refugee Integration: a Quantitative Analysis of Integration and Social Policy Outcomes. Journal of Social Policy, 46(02), 211-230. https://doi.org/10.1017/S0047279416000775

Clemens, M., Huang, C., \& Graham, J. (2018). The Economic and Fiscal Effects of Granting Refugees Formal Labor Market Access (No. 496). Retrieved from www.cgdev.orgwww.cgdev.org

Don, Z. M., \& Lee, C. (2014). Representing immigrants as illegals, threats and victims in Malaysia: Elite voices in the media. Discourse and Society, 25(6), 687-705. https://doi.org/10.1177/0957926514536837

Dubus, N. (2017). Integration or Building Resilience: What Should the Goal Be in Refugee Resettlement? Journal of Immigrant and Refugee Studies, O(0), 1-17. https://doi.org/10.1080/15562948.2017.1358409

Ghazali, M. S., Peck Leong, T., \& Subramaniam, G. (2018). Toward Understanding Livelihood Framework of Refugees in Malaysia: a Conceptual Paper. Journal of Islamic, Social, Economics and Development, 3(14), 37-43. Retrieved from www.jised.com

Imran, A.-, \& Mohammad. (2014). The Rohingya Refugees in Bangladesh : A Vulnerable Group in Law and Policy. Journal of Studies in Social Sciences, 8(2), $226-253$. International Labour Organization. ILO's Support to Refugees and Host Communities in Turkey. , ILO Office for Turkey (2019).

JREC. (2019). Work Preparedness Workshop (WPW)- Rohingya Refugees. Retrieved May 13, 2020, from JREC website: https://jrecmalaysia.com/work-preparednessworkshop-wpwl

Kaos, J. (2017). First batch of 300 refugees to be placed in selected companies. The Star Online. Retrieved from https://www.thestar.com.my/news/nation/2017/02/03/pilot-project-in-aid-of-rohingya-first-batch-of-300-refugees-to-be-placed-in-selected-companies/

Kaur, A. (2008). International Migration and Governance in Malaysia : Policy and Performance. UNEAC Asia Papers, (22), 4-18.

Kaur, M. (2020, May 6). Rohingya resettled in the US appeals to Malaysians amid anti-refugee hate speech . Free Malaysia Today. Retrieved from https://www.freemalaysiatoday.com/category/nation/2020/05/06/rohingya-resettled-in-the-us-appeals-to-malaysians-amid-anti-refugee-hate-speech/

Lokman. (2017). UNHCR cardholders not keen to work in the work plantation and manufacturing sectors. The Star Online. Retrieved from https://www.nst.com.my/news/nation/2017/07/256461/unhcr-cardholders-not-keen-work-work-plantation-and-manufacturing-sectors

Nungsari, M., \& Flanders, S. (2018). A COMPREHENSIVE STUDY OF ROHINGYA CONSTRUCTION WORKERS IN PENINSULAR MALAYSIA AND RECOMMENDATIONS FOR A FUTURE WORK PILOT PROGRAM. Retrieved from http://www.melatinungsari.com/uploads/2/3/6/3/23631450/finalreport-mnsf.pdf

OECD. (2016). Hiring refugees-What are the opportunities and challenges for employers? Retrieved from https://www.oecd.org/els/mig/migration-policy-debates-10.pdf

Rodriguez, F., Kallas, G., \& ten Zijthoff, S. (2019). Refugee Work Rights Report: Refugee Access to Fair and Lawful Work in Asia. Retrieved from https://asylumaccess.org/wp-content/uploads/2019/11/Asia-RWR_FINAL.pdf

S.B, R. (2020, April 26). Please don't hate us, Rohingya plead with Malaysians | The Star. The Star Online. Retrieved from https://www.thestar.com.my/news/focus/2020/04/26/please-don039t-hate-us-rohingya-plead-with-malaysians

SUARAM. (2008). Undocumented migrants and refugees in Malaysia: Raids, Detention and Discrimination. Retrieved from https://www.fidh.org//MG/pdf/MalaisieCONJ489eng.pdf

The Sun Daily. (2017, February 2). Pilot project to allow Rohingya UNHCR card holders work legally to begin from March: Zahid. Retrieved May 13, 2020, from The Sun Daily website: https://www.thesundaily.my/archive/2148173-ITARCH425058

Todd, L., Amirullah, A., \& Shin, W. Y. (2019). The Economic Impact of Granting Refugees in Malaysia the Right to Work (No. 60). Retrieved from www.ideas.org.my UNHCR. (2016). UNHCR Statistical Yearbook 2016. 1-216.

UNHCR. (2017). Global Trends Forced Displacement in 2016. (June).

UNHCR. (2020a). Pakistan | Global Focus. Retrieved May 13, 2020, from UNHCR website: http://reporting.unhcr.org/pakistan

UNHCR, M. (2020b). UNHCR - Figures at a Glance in Malaysia. Retrieved May 12, 2020, from https://www.unhcr.org/en-my/figures-at-a-glance-in-malaysia.html

Wake, C., \& Cheung, T. (2016). Livelihood strategies of Rohingya refugees in Malaysia "We want to live in dignity." Retrieved from http://www.odi.org/hpg 
Yasmin, P. N. ., Daniel, T. ., \& Fauzi, N. (2019). Granting Refugees Permission to Work in Malaysia. ISIS Malaysia National Interest Analysis No. 1. Kuala Lumpur.

Zaafir, M. S. (2020, May 12). 'Afghan women in Pakistan in safe hands.' Retrieved May 13, 2020, from International The News website: https://www.thenews.com.pk/print/626457-afghan-women-in-pakistan-in-safe-hands

Zetter, R., \& Ruaudel, H. (2016a). Refugees' Right to Work and Access to Labor Markets - An Assessment, Part II: Country Cases. KNOMAD Study, September(September), 49 .

Zetter, R., \& Ruaudel, H. (2016b). Refugees' Right to Work and Access to Labor Markets - An Assessment. In The Global Knowledge Partnership on Migration and Development. 